\title{
Primary Hyperaldosteronism: Pitfalls in the Diagnosis and a not so Peculiar Evolution - Case Report
}

\author{
Joao Martin Martins ${ }^{\text {a, b }}$, Rui Melo Cabral ${ }^{\mathrm{a}}$, Sonia do Vale ${ }^{\mathrm{a}}$, \\ Ana Filipa Martins ${ }^{\mathrm{a}}$, Ana Raquel Gomes ${ }^{\mathrm{a}}$
}

\begin{abstract}
Primary hyperaldosteronism is now assumed to account for $10-15 \%$ of all cases of non selected high blood pressure. The differential diagnosis between bilateral hyperplasia and unilateral adenoma remains however a medical challenge, and the pathogenic stimulus for hyperplasia is still unknown. HS, a female patient aged 32, presented with High Blood Pressure and hypokalemia. An elevated aldosterone/renin ratio and non-suppressed aldosterone levels after saline infusion confirmed the diagnosis of primary hyperaldosteronism. Negative adrenal scintigraphic examination and a marked aldosterone response in the postural test supported the diagnosis of bilateral hyperplasia, despite the presence of left adrenal nodule in the CT-scan. Tetracosactide stimulation revealed a minor 21-hydroxilase defect and a marked ACTH-dependence of aldosterone secretion. Effective treatment with dexamethasone $1.0 \mathrm{mg}$ every other night was maintained for 9 years, while in the meantime the left adrenal nodule apparently resolved and a right adrenal nodule become apparent. Finally worsening of blood pressure levels and increasing aldosterone concentrations with a positive scintigraphic labelling on the right adrenal gland led to right adrenalectomy that was so far curative. This case report demonstrates bilateral hyperplasia-adenoma evolution and suggests ACTH to be the relevant pathogenic stimulus, allowing for effective long-term treatment with dexamethasone.
\end{abstract}

Keywords: Primary hyperaldosteronism; Hyperplasia; Adenoma

\section{Introduction}

High blood pressure (HBP) occurs in $25 \%$ of the western developed world population [1]. It is now considered that

\footnotetext{
Manuscript accepted for publication August 17, 2012

${ }^{a}$ Endocrine Department, Santa Maria Hospital and Lisbon Medical School, Lisbon, Portugal

${ }^{\mathrm{b} C}$ Corresponding author: Joao Martin Martins, Servico de Endocrinologia, Piso 6, Hospital de Santa Maria, Av. Prof. Egas Moniz, 1649-028 Lisboa, Portugal. Email: jmartinmartins@sapo.pt
}

doi: http://dx.doi.org/10.4021/jem113w up to $15 \%$ may correspond to secondary forms [2-4]. In particularly, recent studies suggest, primary hyperaldosteronism (PA), first described by Conn in 1955, is a rather common condition accounting for more than $10 \%$ of all cases [2-4]. This contrasts sharply with previous consensus, where essential or "idiopathic" hypertension was assumed to account for about $95 \%$ of all cases of non selected HBP [5].

Such a large difference may occur because a simple screening method is now available, namely the aldosterone/ renin ratio and because we now believe many cases of PA occur without the classic hypokalemia, obviously without oedema, and even without HBP, so that in fact we may be diagnosing very early an asymptomatic condition $[2-4,6]$. This occurs commonly in the context of the evaluation of adrenal incidentalomas [7].

HBP due to PA tends to be serious, with more marked evidence of target organ lesions and vascular events and the added risk of arrhythmias [8-10]. A postulated mechanism involving the effects of aldosterone on inflammation and tissue fibrosis and/or in the development of the cardiometabolic syndrome, has been invoked [11-13]. Besides either surgically curative or highly effective medical treatment is available highlighting the importance of this diagnosis.

After the condition is suspected confirmatory dynamic tests are necessary and the distinction between the different forms may be challenging since besides the classical unilateral adenoma (35\%) and the bilateral hyperplasia (60\%), a somehow paradoxical unilateral hyperplasia and a glucocorticoid remediable form have been described and treatment options are radically different [2-4]. Furthermore regarding the unilateral or bilateral hyperplasia, the stimulus for the persistent stimulation remains unidentified, and it seems possible that endocrine hyperplasia may evolve to autonomous adenomas [14]. In this regard, imaging methods, for example, adrenal computed tomography (CT) and nuclear magnetic resonance (NMR), may add to the confusion, given the high incidence of silent incidentalomas, the high probability of missing small $(<1 \mathrm{~cm})$ adenomas, and the inability to definitively distinguish adenomas and uni- or bilateral hyperplasia $[2-4,15,16]$.

Diagnostic work out generally includes screening tests in selected high risk groups, mainly ambulatory paired ran- 


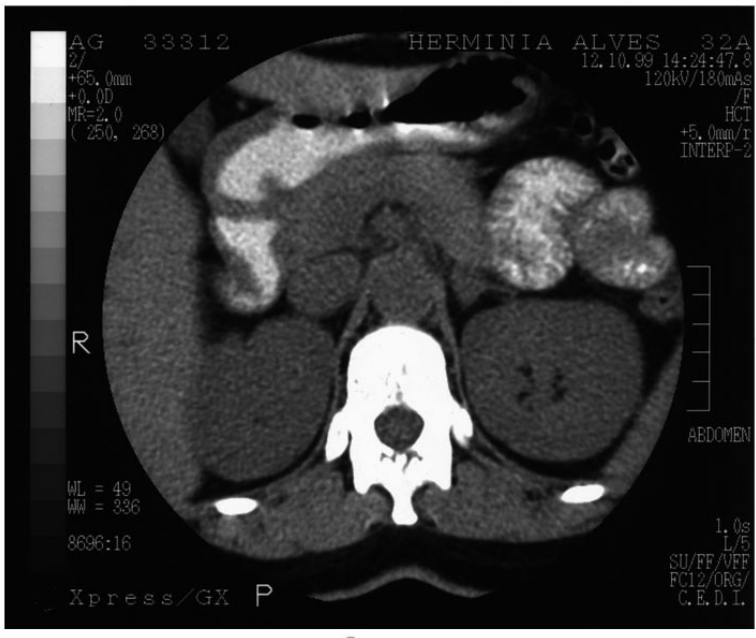

a

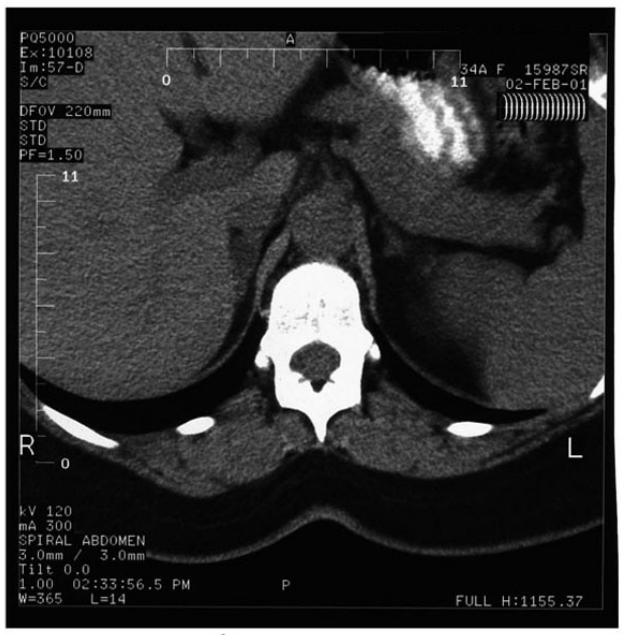

b

Figure 1. Abdominal CT scan. (a) 1999 - a small nodular lesion around $1 \mathrm{~cm}$ is noted in the left adrenal gland; no abnormalities were found regarding the right adrenal gland. (b) 2001 - a nodular lesion hypodense with $15 \mathrm{~mm}$ maximal diameter, is noted in the right adrenal gland, which is not apparent in the previous scan; no apparent lesions were found regarding the left adrenal gland.

dom plasma aldosterone and renin, at specific timetables and postural conditions, optimally with an unrestricted salt diet and no anti-hypertensive drugs, but certainly without aldosterone receptor antagonists like spironolactone or eplerenone - sensitivity and specificity above 90\% [2-4, 17-19]. Confirmatory tests must then be used, either the intravenous saline infusion test or an alternative like the oral sodium loading test or fludrocortisone suppression test - sensitivity and specificity again above 90\% [2-4, 20]. Finally one must proceed to the differential diagnosis: 1) adrenal CT - only $25 \%$ sensitivity for small adenomas $<1 \mathrm{~cm}$ and an accuracy of $50 \%$ regarding the distinction between adenomas and bilateral hyperplasia [2-4, 21-24]; 2) adrenal venous sampling - now considered the reference test, it is not without risks, it is technically demanding and theoretically confusing with sequential instead of simultaneous sampling used, the need to correct for cortisol and tetracosactide stimulation although a sensitivity and specificity above $95 \%$ have been reported [2-4, 21-24]. Regarding catecholamine secretion however, lateralization was found to be a normal finding
[25]. Other historical tests seem to have lost favour like ${ }^{131} \mathrm{I}-$ 19-iodocholesterol or $6 \beta-{ }^{131} \mathrm{I}$ iodomethyl-19-norcholesterol (NP-59) scintigraphy, the postural stimulation test and the measurement of 18-hydroxycorticosterone [2-4]. However regarding tests used in the differential diagnosis one must accept that they are either technically demanding and available only at selected sites or theoretically confusing [26].

We now report a case of PA where diagnostic workout proved confusing, but in the end probably very easy. This case demonstrates that bilateral hyperplasia - adenoma evolution can occur, and suggests ACTH to be the pathogenic stimulus, underlining the long term effectiveness of dexamethasone treatment.

\section{Case Report}

HS, a Caucasian female patient, aged 32, unskilled worker, divorced, living in Lisbon, was referred to the Endocrine Out Patient Department of a public central hospital, on October

Table 1. Saline Suppression Test ( $\mathrm{NaCl} 0.9 \%, 2,000 \mathrm{~mL}$, ev, Over $4 \mathrm{~h}$ )

\begin{tabular}{|c|c|c|c|c|}
\hline & $\mathbf{O} \mathbf{h}$ & $2 \mathrm{~h}$ & $4 \mathrm{~h}$ & RV \\
\hline $\operatorname{Renin}(\mu \mathrm{U} / \mathrm{mL})$ & 1 & 0.8 & 0.7 & $(\mathrm{D}-1-20 \mu \mathrm{U} / \mathrm{mL})$ \\
\hline Aldosterone (pg/mL) & 310 & 150 & 226 & $(\mathrm{D}-10-160 \mathrm{pg} / \mathrm{mL})$ \\
\hline
\end{tabular}

Renin and aldosterone were measured by radioimmunoassay (Diagnostic Products Corporation, Los Angeles); intra- and interassay coefficients of variation were less than $10 \%$. Baseline decubitus (D) reference values (RV) are presented. 
Table 2. Ambulatory Testing (4 h Brisk Walking)

\begin{tabular}{|c|c|c|c|}
\hline & Before & After & $\mathbf{R V}$ \\
\hline $\operatorname{Renin}(\mu \mathrm{U} / \mathrm{mL})$ & 1 & 2 & $(\mathrm{D}-1-20 \mu \mathrm{U} / \mathrm{mL})(\mathrm{S}-2-60 \mu \mathrm{U} / \mathrm{mL})$ \\
\hline Aldosterone (pg/mL) & 280 & 367 & $(\mathrm{D}-10-160 \mathrm{pg} / \mathrm{mL})(\mathrm{S}-40-310 \mathrm{pg} / \mathrm{mL})$ \\
\hline
\end{tabular}

Reference values (RV) are present for the decubitus (D) and standing (S) position.

1999, because of HBP and hypokalemia.

HBP was diagnosed 6 months before, on a routine medical examination and confirmed by several random measurements of 150 - 160/90 - $100 \mathrm{mmHg}$. The patient was asymptomatic with no headaches, no visual disturbances, no oedema, no dyspnea, no chest pain, no palpitations and no syncope. There were no episodes of sudden high blood pressure with or without anxiety and adrenergic symptoms, no weight loss, no renal disease, including renal stones, and no changes of body weight or menstrual cycles. At the time the patient was not using any medications, including contraceptive pills and she did not smoke nor did she regularly drink alcoholic beverages. She did not present any other known medical illness and was never submitted to a surgical intervention. Menarche occurred at age 12, followed by regular menstrual cycles. She was married at 20 years and used contraceptive pills for some time. She was pregnant once at 21 years, with an uneventful pregnancy not complicated by high blood pressure, gestational diabetes or pre-eclampsia. Both parents were still alive, aged 53 and 50 years, with no high blood pressure. There was no family record for other endocrine or renal diseases.

The patient presented several prior analytical reports with no relevant abnormalities, except for persistent hypokalemia (2.6 - $2.8 \mathrm{mEq} / \mathrm{L}$ (reference range 3.5 - $4.5 \mathrm{mEq} / \mathrm{L}$ )). A previous abdominal CT scan revealed a nodular lesion of $1 \mathrm{~cm}$ on the left adrenal gland with no other abnormalities
(Fig. 1a). She was using Ramipril $5 \mathrm{mg}$, once daily with apparent success regarding the control of blood pressure levels and no significant side effects. Slow-releasing Nifedipine 30 mg was substituted for, and admission to the Endocrine In Patient department was arranged for two weeks later, after a weekend without any medication.

On admission, physical examination revealed an apparently healthy adult female subject, alert, oriented, with no cognitive disturbances and an adequate emotional behaviour. She looked her age, with slight excess weight, and moved normally with no apparent limitations. Her body temperature was normal with no respiratory distress, no cyanosis, and no peripheral oedema. Height: $1.54 \mathrm{~m}$; Weight: $64 \mathrm{~kg}$ (without shoes or coats); Umbilical perimeter: $81 \mathrm{~cm}$; Hip perimeter: $99 \mathrm{~cm}$. Dorsal decubitus blood pressure was 190/110 $\mathrm{mmHg}$ in the right arm and $180 / 110 \mathrm{mmHg}$ in the left arm and 190/110 mmHg in the right leg; standing right arm blood pressure was $170 / 100 \mathrm{mmHg}$. Heart beats varied between $82-86 \mathrm{bpm}$ and respiratory excursions were large at $16 \mathrm{cpm}$. Head and neck examination did not reveal any relevant findings, namely regarding the thyroid or the neck vessels. The thorax was of normal shape with no skin or breast lesions and no apparent abnormalities on cardiopulmonary auscultation, except for a systolic murmur grade II/VI and a slightly increased S2 sound at the second right intercostal space. The abdomen was smooth, painless on palpation with no tenderness and moved freely with the respiratory excursion. There

Table 3. Tetracosactide Test (250 $\mu \mathrm{g}$ ACTH1-24, ev)

\begin{tabular}{|c|c|c|c|c|}
\hline & $0 \mathrm{~min}$ & $30 \mathrm{~min}$ & $60 \mathrm{~min}$ & $\mathbf{R V}$ \\
\hline Cortisol ( $\mu \mathrm{g} / \mathrm{dL})$ & 19 & 58 & 56 & $(8 \mathrm{~h}$ am $-4-23 \mu \mathrm{g} / \mathrm{dL})$ \\
\hline 17-hydroxiprogesterone $(\mathrm{ng} / \mathrm{mL})$ & 3 & 10 & 7 & $(\mathrm{FF}-0.2-1.8 \mathrm{ng} / \mathrm{mL})$ \\
\hline 11-deoxi-cortisol (ng/mL) & 1 & 4 & 4 & $(<8 \mathrm{ng} / \mathrm{mL})$ \\
\hline $\operatorname{Renin}(\mu \mathrm{U} / \mathrm{mL})$ & 1 & 1 & 2 & $(1-20 \mu \mathrm{U} / \mathrm{mL})$ \\
\hline Aldosterone $(\mathrm{pg} / \mathrm{mL})$ & 210 & 1,030 & 80 & $(10-160 \mathrm{pg} / \mathrm{mL})$ \\
\hline
\end{tabular}

Cortisol was measured by chemiluminoscence immunoassay and 17-hydroxyprogesterone ad 11-deoxi-cortisol were measured by radioimmunoassay (Diagnostic Products Corporation, Los Angeles). Reference values (RV) are presented at $8 \mathrm{~h}$ am, or in the follicular phase (FF). 


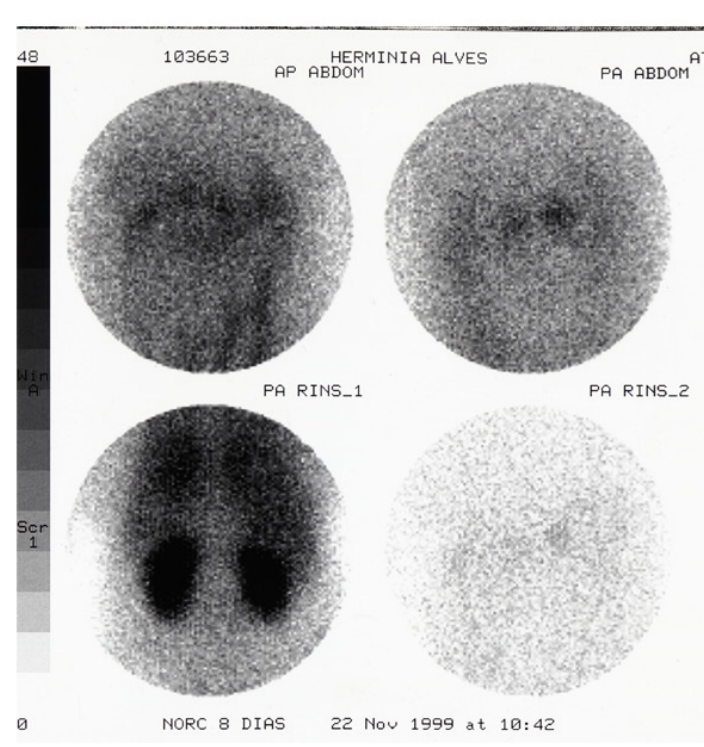

a

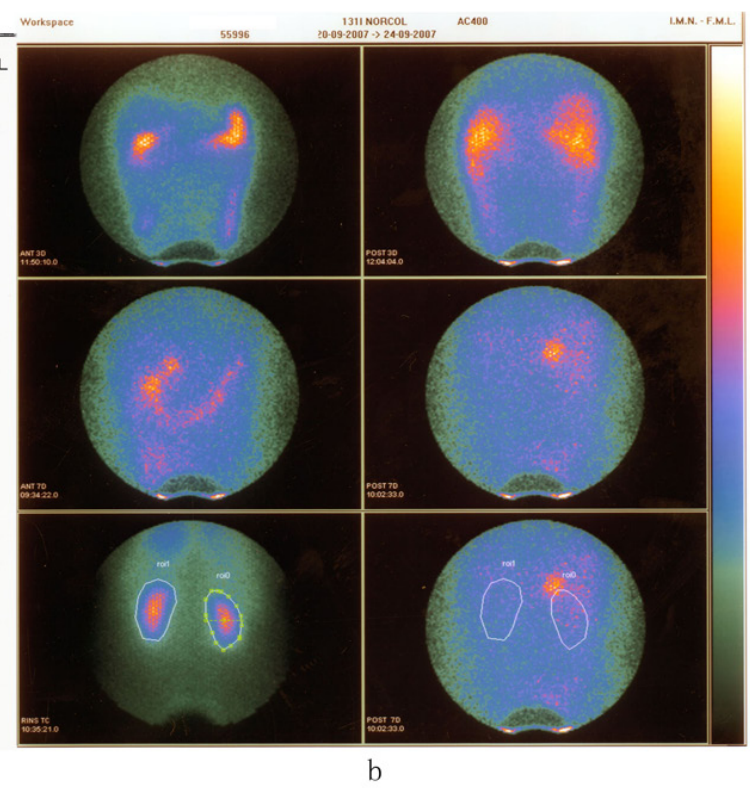

Figure 2. ${ }^{131}$ I Norcholesterol Scintigraphic examination. (a) 1999 - images were obtained at the 3rd, 5th and 8th day; slight hyperfixation is found over both the adrenals. (b) 2007 - images were obtained at the 3 rd and 7th day; clear hyperfixation above the upper pole of the right kidney more evident at the 7 th day.

was no evidence of enlarged liver or spleen, and no bruits were found over the epigastric, periumbilical or lumbar areas. The upper and lower members were apparently normal, without oedema and peripheral pulses were rhythmic and symmetric. Neurologic examination was negative.

During her 7-day hospital stay, repeated routine analytical evaluation failed to show any relevant finding except for persistent hypokalemia $(2.4-2.8 \mathrm{mEq} / \mathrm{L})$; in particularly, there were no hematologic abnormalities, kidney and liver function tests were normal, as was acid-base status, mineral metabolism, glucose, proteins and lipids. Thorax x-ray was normal with no evidence of an increased or abnormal cardiac shadow and the EKG showed a normal sinus rhythm (75/min), with normal PR, QRS and QT intervals, an electric axis at $+30^{\circ}$ in the vertical plan and a transition between negative and positive complexes at V3-V4 in the horizontal plane. $\mathrm{R}$ was always less than $15 \mathrm{~mm}$ and $\mathrm{R}+\mathrm{S}$ less than $35 \mathrm{~mm}$; no other abnormalities could be found. Fundoscopic examination was negative for signs of hypertensive disease and $24 \mathrm{~h}$ urinary microalbumin was negative.
Twenty-four hours blood pressure measurements were obtained with mean values in the $24 \mathrm{~h}$ period of $123 / 80$ $\mathrm{mmHg}, 134 / 89 \mathrm{mmHg}$ during the day period $(8-22 \mathrm{~h})$ and $109 / 68 \mathrm{mmHg}$ in the night period $(22-8 \mathrm{~h})$. Systolic blood pressure was greater than $140 \mathrm{mmHg}$ at $30 \%$ of the measurements and diastolic blood pressure was greater than 90 $\mathrm{mmHg}$ at $31 \%$ of the time.

Routine endocrine evaluation was normal regarding thyroid, parathyroid, pituitary or gonadic function. ACTH and cortisol were also normal with the classical circadian rhythm; 24 h-urinary excretion of adrenaline, noradrenaline, metanephrine, normetanephrine and vanilmandelic acid were normal and so were androgen levels including total and free testosterone, androstenedione, dehydroepiandrosteronesulphate, 17-hydroxyprogesterone and 11-deoxicortisol.

However analytical evaluation revealed repeated low renin levels: $0.5-0.8 \mu \mathrm{U} / \mathrm{mL}$ (reference range $1-20 \mu \mathrm{U} / \mathrm{mL}$ ) with high aldosterone levels: $190-240 \mathrm{pg} / \mathrm{mL}$ (reference range $10-160 \mathrm{pg} / \mathrm{mL}$ ) and an increased 24 h-urinary excretion of aldosterone: $48-56 \mu \mathrm{g} / 24 \mathrm{~h}$ (reference range $6-25$

Table 4. Saline Suppression Test ( $\mathrm{NaCl} 0.9 \%, 2,000 \mathrm{~mL}$, ev, Over $4 \mathrm{~h}$ )

\begin{tabular}{lcccc}
\hline & $\mathbf{0 ~ h}$ & $\mathbf{2}$ h & $\mathbf{4}$ h & $\mathbf{R V}$ \\
\hline Renin $(\mu \mathrm{U} / \mathrm{mL})$ & 0.7 & 0.9 & 0.5 & $(1-20 \mu \mathrm{U} / \mathrm{mL})$ \\
Aldosterone $(\mathrm{pg} / \mathrm{mL})$ & 350 & 320 & 560 & $(10-160 \mathrm{pg} / \mathrm{mL})$ \\
\hline
\end{tabular}


Table 5. Ambulatory Testing (4 h Brisk Walking)

\begin{tabular}{|c|c|c|c|}
\hline & Before & After & $\mathbf{R V}$ \\
\hline $\operatorname{Renin}(\mu \mathrm{U} / \mathrm{mL})$ & 0.7 & 0.6 & $(\mathrm{D}-1-20 \mu \mathrm{U} / \mathrm{mL})(\mathrm{S}-2-60 \mu \mathrm{U} / \mathrm{mL})$ \\
\hline Aldosterone (pg/mL) & 280 & 580 & $(\mathrm{D}-10-160 \mathrm{pg} / \mathrm{mL})(\mathrm{S}-40-310 \mathrm{pg} / \mathrm{mL})$ \\
\hline
\end{tabular}

$\mu \mathrm{g} / 24 \mathrm{~h}$ ). These measurements were obtained in the supine position with a normal saline diet and no anti-hypertension drugs.

A saline suppression test was performed after an overnight fast while the patient remained in bed, with $2 \mathrm{~L}$ normal saline infused over $4 \mathrm{~h}$. Results are presented in Table 1.

An ambulatory test was then performed again after an overnight fast, with blood samples obtained first while the patient was still in bed, and then after $4 \mathrm{~h}$ of brisk walking. The following results were obtained (Table 2).

A Synacthen test was finally performed again after an overnight fast. Tetracosactide (ACTH1-24) $250 \mu \mathrm{g}$ was administered ev at time 0 , and blood was then collected at 30 and $60 \mathrm{~min}$. Results are presented in Table 3.

Nor-( $\left.{ }^{125} \mathrm{I}\right)$ iodomethyl-colesterol isotope imaging under dexamethasone $0.5 \mathrm{mg}, 6 / 6 \mathrm{~h}$ for $48 \mathrm{~h}$, revealed "slight fixation at both adrenals, more so on the right, that is probably non relevant given the information regarding a nodular lesion on the left adrenal" (Fig. 2a).

A presumptive diagnosis of PA - bilateral hyperplasia was assumed given the ambulatory test, the tetracosactide test and non lateralization of scintigraphic labelling of the adrenals, while the nodular lesion at the left adrenal was not judged functionally relevant. Medical treatment was decided upon with a hyposaline diet and dexamethasone $1.0 \mathrm{mg}$ at bed time every other day. Under this treatment, and for 2 years blood pressure was normal $(<140 / 90 \mathrm{mmHg})$ with normal serum potassium and no relevant side-effects.

On January 2001, the patient now aged 33, was again admitted to the Endocrine Unit after a week end free of medication. The saline suppression test (Table 4) and the ambulatory test (Table 5) were again repeated. An adrenal CT scan was again obtained and a nodular lesion of $15 \mathrm{~mm}$ diameter, with low density and smooth contours was found in the right adrenal, with no apparent abnormalities on the left (Fig. 1b). Previous diagnosis and therapy were resumed after discharge.

On March 2002, a planned pregnancy occurred after dexamethasone substitution for alpha-methyldopa $500 \mathrm{mg}$ tid. Pregnancy was uneventful with normal blood pressure levels and no pre-eclampsia or eclampsia. A boy was born with normal weight and normal vitality at 5 and $10 \mathrm{~min}$. Phallopian tubes were ligated at the time and dexamethasone was again resumed $1.0 \mathrm{mg}$, at bedtime every other day.

On August 2005, the patient now aged 37 was again admitted to the Endocrine Department because of acute gastroenteritis with serious hypokalemia $(1.8 \mathrm{mEq} / \mathrm{L})$. The patient denied missing any drug schedule and she was not hypertensive. There was no fever and the stools were without blood, mucus or pus. C-Reactive protein was negative. Again high serum aldosterone levels $(280 \mathrm{pg} / \mathrm{mL})$ and low renin levels $(0.7 \mu \mathrm{U} / \mathrm{mL})$ were measured. Three days later after correction of the clinical condition and serum potassium the patient was discharged and previous medication was resumed.

Again for 2 years, evolution was uneventful with normal blood pressure levels and normal serum potassium, and no relevant side effects.

Since 2008, blood pressure levels began to increase despite drug treatment and spironolactone $100 \mathrm{mg} /$ day and later bisoprolol $5 \mathrm{mg} /$ day were added. At this time there was still no evidence of target-organ lesions, namely regarding the heart or the kidneys. At the end of 2008 the patient was again admitted to the Endocrine Department because of resistant high blood pressure, although with no specific symptoms and still with a normal serum potassium levels. Dynamic tests were again repeated and are shown in Tables 6 and 7. A new scintigraphic examination with 19-noriodomethylcolesterol was performed hat revealed persistent and

Table 6. Saline Suppression Test (2 L Normosaline Infused ev Over 4 h)

\begin{tabular}{lcccc}
\hline & $\mathbf{0 ~ h}$ & $\mathbf{2} \mathbf{h}$ & $\mathbf{4}$ h & \\
\hline Renin $(\mu \mathrm{U} / \mathrm{mL})$ & 0.6 & 0.7 & 0.7 & $(1-20 \mu \mathrm{U} / \mathrm{mL})$ \\
Aldosterone $(\mathrm{pg} / \mathrm{mL})$ & 716 & 267 & 219 & $(10-160 \mathrm{pg} / \mathrm{mL})$ \\
\hline
\end{tabular}


Table 7. Ambulatory Test (4 h of Brisk Walking)

\begin{tabular}{|c|c|c|c|}
\hline & $\mathbf{0 ~ h}$ & $4 \mathrm{~h}$ & RV \\
\hline $\operatorname{Renin}(\mu \mathrm{U} / \mathrm{Ml})$ & 0.5 & 0.4 & $(\mathrm{D}-1-20 \mu \mathrm{U} / \mathrm{mL})(\mathrm{S}-2-60 \mu \mathrm{U} / \mathrm{mL})$ \\
\hline Aldosterone (pg/mL) & 631 & 1,000 & $(\mathrm{D}-10-160 \mathrm{pg} / \mathrm{mL})(\mathrm{S}-40-310 \mathrm{pg} / \mathrm{mL})$ \\
\hline
\end{tabular}

abnormal fixation at the right adrenal gland (Fig. 2b). Surgery was decided and performed on March 2009; the right adrenal gland with $24 \times 1 \mathrm{~mm}$ and $9 \mathrm{~g}$ was removed and an adenoma was identified. There was no reference to adrenal hyperplasia on the remaining gland.

Since the surgery the patient remains normotensive 130 - 140/80 - $85 \mathrm{mmHg}$ without medication and a $24 \mathrm{~h}$ blood pressure ambulatory monitoring was again preformed with normal blood pressure levels along the $24 \mathrm{~h}$ period.

\section{Discussion}

This case begins with the classical presentation of hyperaldosteronism: a young woman presents with recent onset HBP and hypokalemia. Hypokalemia is indeed highly suggestive of hyperaldosteronism, even if it is present in only between $10-40 \%$ of the cases [2-4]. Furthermore the patient presented with what can be called Inappropriate High Blood Pressure as defined by Kaplan [5] justifying a diagnostic work out for secondary forms of HBP.

Evaluation while in the hospital and free of relevant medications confirmed: 1) HBP - even if in hospital $24 \mathrm{~h}$ blood pressure levels were much lower than previous readings in the ambulatory setting; 2) hypokalemia; 3) increased aldosterone plasma levels with suppressed renin levels and a markedly increased aldosterone/renin ratio; 4) $24 \mathrm{~h}$ urinary aldosterone excretion was also increased; 5) furthermore the saline suppression test showed non suppressible aldosterone.

The diagnosis of PA was thus unequivocal. An increased aldosterone/renin ratio has $78 \%$ sensitivity and $83 \%$ specificity for PA, while the saline suppression test has $90 \%$ sensitivity and $84 \%$ specificity for hyperaldosteronism [2-4].

Diagnostic work out for differential diagnosis of PA is controversial, generally non definitive and furthermore some methods may not be available at every medical centre [2-4, 26].

Adrenal CT scan is recommended as the initial test for the differential diagnosis and also to exclude large masses as this may raise the suspicion of carcinoma [3]. The CT scan of the adrenals revealed a hypodense round lesion of $10 \mathrm{~mm}$ in the left adrenal gland with no apparent abnormalities in the right adrenal gland. This test therefore favours unilateral adenoma and according to some authorities unilateral adre- nalectomy is in this setting a reasonable therapeutic option [2]. This method is however of little value at least for itself: 1) more than $10 \%$ of apparent normal subjects present nodular lesions in the adrenal (incidentalomas); 2) while adrenal adenomas responsible for PA are generally small, less than 2 $\mathrm{cm}$, uni- or bilateral hyperplasia may also present small nodules; 3) furthermore responsible or innocent lesions may be at the limit of detection and thus missed [15, 16, 21-24]. In fact CT scans have only a low and variable $45-87 \%$ sensitivity and a variable albeit higher specificity 71-92\% [2-4]. CT scans results are discordant with adrenal vein sampling in up to $23 \%$ of the cases and using only the CT scan up to $34 \%$ of inappropriate surgeries would be preformed [2-4].

The adrenal vein sampling may be considered as the standard test with a reported sensitivity and specificity over $90 \%$ [2-4]. This procedure is however not without risks, technically demanding, requiring dedicated radiologist with acceptable personal experience and is theoretically confusing, since sequential instead of simultaneous sampling is generally used, the aldosterone/cortisol ratio must be used to account for differences regarding the activity level between the adrenals, and since bolus or continuous tetracosactide stimulation is necessary to correct for stress-induced flutuations in adrenal function [2-4, 21-24]. In fact regarding pheochromocytoma and catecholamine secretion by the adrenals, a recent reported study found that in normal glands high lateralization ratios also occur [25]. This method was however not available at the time in our institution.

We performed an ambulatory test that revealed an aldosterone response suggesting at least partial angiotensin dependence and therefore favours adrenal hyperplasia. The ambulatory test by itself is not a definitive test but a response such as the one found in this case favours adrenal hyperplasia ( $88 \%$ of the cases) while a decrease suggesting partial ACTH sensitivity favours adenoma ( $83 \%$ of the cases). This test seems to have an overall accuracy of $85 \%[2,3]$.

Scintigraphic examination with nor-iodo-methylcholesterol was performed under dexamethasone and revealed "slight fixation on both adrenals, more so on the right." This examination has an overall precision of $73 \%$, but may miss small lesions. It suggested however the non functional nature of the lesion identified in the left adrenal gland by CT scan and again favours the diagnosis of bilateral hyperplasia [24]. 
We selected to perform a Synacthen test that is generally not used $\mathrm{n}$ this specific diagnostic work out. Based on our personal previous experience we wanted to exclude minor/ late onset forms of congenital adrenal hyperplasia and also to evaluate the ACTH-dependence of aldosterone secretion [27]. The tetracosactide test revealed both a possible minor 21-hydroxylase defect [28] and a marked aldosterone response to synthetic ACTH. Several remarks may be made at this point: 1) ACTH dependence in the context of ambulatory testing is generally considered to suggest an adenoma [2-4]. 2) A glucocorticoid remediable hyperaldosteronism could have been suspected; however this is rare, less than $1 \%$ of all cases of primary aldosteronism, and clinical presentation is different with a positive family history and early onset of severe high blood pressure refractory to conventional treatment [2-4]; although genetic testing or the measurement of 18-hydroxycortisol or 18-oxyocortisol were not available and were not performed, we suppose this is not the case; in fact we have previously found this marked ACTHdependence to be very common in patients with minor/late onset forms of congenital adrenal hyperplasia [27]; the fact remains however of a marked ACTH-dependence for aldosterone secretion.

A presumptive diagnosis of PA, probable bilateral adrenal hyperplasia was established, surgery was considered inappropriate and medical treatment was decided. In fact in favour of adrenal hyperplasia were the results of the ambulatory tests and negative scintigraphic examination, while hypokalemia and a lesion on the left adrenal gland favoured adenoma. Since a decision on medical treatment can always be later reversed while the opposite is not true and medical treatment is available although not curative, our decision seems justified.

Medical treatment was begun with dexamethasone 1.0 $\mathrm{mg}$ once in the evening, every other day and a sodium restricted diet. This treatment is unconventional and spironolactone is generally used instead; spironolactone in the female gender presents unpleasant side effects namely oligoamenorhea [2-4]; dexamethasone was preferred instead because of the dramatic aldosterone response in the tetracosactide test, and was supported by the minor/late onset defect of 21-hydroxylase. In fact this therapy was very effective for 9 years, again suggesting a strong ACTH-dependence of aldosterone secretion that maybe in some cases, namely those with minor defects of adrenal steroidogenesis may be the relevant stimulus for the hyperplasia. Meanwhile an episode of acute gastroenteritis with hypokalemia occurred and a planned pregnancy was uneventful with dexamethasone substitution for alpha-methyldopa.

Much more interestingly however the lesion on the left adrenal gland resolved after one year and a larger $13 \mathrm{~mm}$ lesion was found in the right adrenal gland that persisted with almost no change for 9 years (a $4 \mathrm{~mm}$ increase). Had we decided on left adrenalectomy which as noted, is considered a reasonable therapeutic option, an unnecessary and probably non effective procedure would have been done. Although a technical error of interpretation may be assumed, at the limit of detection of the CT scan, pointing to the relatively low accuracy of this method in this specific setting, we consider it more probable to reflect the dynamic nature of the hyperplastic process.

Nine years later blood pressure levels significantly increased in a permanent way and resisted therapy with dexamethasone, spironolactone and bisoprolol. The patient was again admitted to the Endocrine Unit and the dynamic evaluation was repeated. Again nonsuppressible aldosterone levels were found with a marked aldosterone increase on ambulation. It must be note however that both baseline and post-stimulation levels of aldosterone were much higher than on first examination, highlighting the apparent evolutive nature of the process. Scintigraphic examination now revealed intense and persistent fixation on the right adrenal gland. Surgery was decided that confirmed an adenoma on the right adrenal gland; no mention was made regarding evidence for hyperplasia in gland although this probably reflect unawareness of its relevance. Since surgery the patient is normotensive with no medications.

This unusual case and follow-up illustrate several relevant points.

The diagnosis of PA is easy, but the differential diagnosis between adenoma and bilateral hyperplasia may become very difficult. If this is so, regarding equivocal cases it may be better to choose medical therapy and follow the patient. This option if of course easily reversible, controls blood pressure levels and prevents the development of target organ lesions. This option has the added advantage that bilateral hyperplasia may later become autonomous unilateral adenoma. Using this rational approach adrenal vein sampling may be at least less indispensable.

Findings of the adrenal CT scan may be very misleading. Technical reasons are well known but it may be worth emphasising that at the detection limit of the method, adrenal nodules may "appear" and "disappear", namely, may become apparent or inapparent along time in bilateral hyperplasia.

Aldosterone secretion may at least in some cases, like this one, and more usual in the context of minor late onset defects of adrenal steroidogenesis be strongly ACTH-dependent. It is worth noting that aldosterone increase after ACTH was at least as high as the cortisol rise. ACTH may indeed be the stimulus leading to bilateral hyperplasia. At the same token this data suggests an alternative therapeutic option like dexamethasone that in this case at least, was long term effective.

An apparent evolution from bilateral hyperplasia to autonomous unilateral adenoma is strongly suggested in this case. Initial work out suggested adrenal hyperplasia, namely the ambulatory test and the scintigraphic examination. Follow up of the patient reinforces this evidence. A nodule was 
first found on the left adrenal and later "resolved" while a nodule was found in the right adrenal. Strong ACTH dependence would lead first to a general hyperplasia not to a solitary nodule. Dexamethasone therapy would not be expected to be effective regarding an autonomous adenoma. In fact in the long term evolution dexamethasone lost efficacy while aldosterone levels markedly increased both baseline and post-stimulation. Adenoma autonomisation seems best fit in this change. Unfortunately we had no report regarding evidence of hyperplasia in removed gland, but probably one should look specifically for it. It is possible that in the long term other adenoma may appear and if so blood pressure will rise again. Follow up must therefore be maintained.

\section{Consent}

Written informed consent was obtained from the patient for publication of this case report and the accompanying images.

\section{Competing Interests}

All authors declare that they have no competing interests.

\section{Authors' Contributions}

JMM assured the medical care of the patient, including the selection of appropriate diagnostic tests and therapeutic interventions. He also wrote the first and final version of this MS.

RMC wrote an intermediate version of the MS and collected the relevant bibliography. He also contributed deeply to the final version of the MS.

SV assisted JMM regarding the medical care of the patient, including the clinical discussion of relevant diagnostic tests and therapeutic measures. She contributed all along the writing of the first and final version of the MS.

AFM and ARG contributed fundamentally to the final version of the MS.

All authors give final approval of the version hereby submitted for publication.

\section{References}

1. Hajjar I, Kotchen TA. Trends in prevalence, awareness, treatment, and control of hypertension in the United States, 1988-2000. JAMA. 2003;290(2):199-206.

2. Young WF: Endocrine Hypertension. In Williams Textbook of Endocrinology.11th edition. Edited by Kroneberg HM, Melmed S, Polonsky KS, Larsen PR. Philadelphia: Saunders Elsevier; 2008: 505-537.
3. Funder JW, Carey RM, Fardella C, Gomez-Sanchez CE, Mantero F, Stowasser M, Young WF, Jr., et al. Case detection, diagnosis, and treatment of patients with primary aldosteronism: an endocrine society clinical practice guideline. J Clin Endocrinol Metab. 2008;93(9):32663281.

4. Stowasser M. Update in primary aldosteronism. J Clin Endocrinol Metab. 2009;94(10):3623-3630.

5. Kaplan NM: Kaplan's Clinical Hypertension. 9th edition. Philadelphia: Lippincott Williams \& Wilkins; 2006.

6. Stowasser M, Sharman J, Leano R, Gordon RD, Ward G, Cowley D, Marwick TH. Evidence for abnormal left ventricular structure and function in normotensive individuals with familial hyperaldosteronism type I. J Clin Endocrinol Metab. 2005;90(9):5070-5076.

7. Caplan RH, Strutt PJ, Wickus GG. Subclinical hormone secretion by incidentally discovered adrenal masses. Arch Surg. 1994;129(3):291-296.

8. Tanabe A, Naruse M, Naruse K, Hase M, Yoshimoto T, Tanaka M, Seki T, et al. Left ventricular hypertrophy is more prominent in patients with primary aldosteronism than in patients with other types of secondary hypertension. Hypertens Res. 1997;20(2):85-90.

9. Milliez P, Girerd X, Plouin PF, Blacher J, Safar ME, Mourad JJ. Evidence for an increased rate of cardiovascular events in patients with primary aldosteronism. J Am Coll Cardiol. 2005;45(8):1243-1248.

10. Born-Frontsberg E, Reincke M, Rump LC, Hahner S, Diederich S, Lorenz R, Allolio B, et al. Cardiovascular and cerebrovascular comorbidities of hypokalemic and normokalemic primary aldosteronism: results of the German Conn's Registry. J Clin Endocrinol Metab. 2009;94(4):1125-1130.

11. Lopez B, Gonzalez A, Diez J. Circulating biomarkers of collagen metabolism in cardiac diseases. Circulation. 2010;121(14):1645-1654.

12. Giacchetti G, Ronconi V, Turchi F, Agostinelli L, Mantero F, Rilli S, Boscaro M. Aldosterone as a key mediator of the cardiometabolic syndrome in primary aldosteronism: an observational study. J Hypertens. 2007;25(1):177-186.

13. Iacobellis G, Petramala L, Cotesta D, Pergolini M, Zinnamosca L, Cianci R, De Toma G, et al. Adipokines and cardiometabolic profile in primary hyperaldosteronism. J Clin Endocrinol Metab. 2010;95(5):2391-2398.

14. Arnold A: Pathogenesis of endocrine tumors. In Williams Textbook of Endocrinology. 11th edition. Edited by Kronenberg HM, Melmed S, Polonsky KS, Larsen PR. Philadelphia: Saunders Elsevier; 2008:1697-1704.

15. Kloos RT, Korobkin M, Thompson NW, Francis IR, Shapiro B, Gross MD. Incidentally discovered adrenal masses. Cancer Treat Res. 1997;89:263-292.

16. Young WF, Jr. Clinical practice. The incidentally discovered adrenal mass. N Engl J Med. 2007;356(6):601-610. 
17. Tiu SC, Choi CH, Shek CC, Ng YW, Chan FK, Ng CM, Kong AP. The use of aldosterone-renin ratio as a diagnostic test for primary hyperaldosteronism and its test characteristics under different conditions of blood sampling. J Clin Endocrinol Metab. 2005;90(1):72-78.

18. Montori VM, Young WF, Jr. Use of plasma aldosterone concentration-to-plasma renin activity ratio as a screening test for primary aldosteronism. A systematic review of the literature. Endocrinol Metab Clin North Am. 2002;31(3):619-632, xi.

19. Perschel FH, Schemer R, Seiler L, Reincke M, Deinum J, Maser-Gluth C, Mechelhoff D, et al. Rapid screening test for primary hyperaldosteronism: ratio of plasma aldosterone to renin concentration determined by fully automated chemiluminescence immunoassays. Clin Chem. 2004;50(9):1650-1655

20. Rossi GP, Belfiore A, Bernini G, Desideri G, Fabris B, Ferri C, Giacchetti G, et al. Prospective evaluation of the saline infusion test for excluding primary aldosteronism due to aldosterone-producing adenoma. J Hypertens. 2007;25(7):1433-1442.

21. Young WF, Stanson AW, Thompson GB, Grant CS, Farley DR, van Heerden JA. Role for adrenal venous sampling in primary aldosteronism. Surgery. 2004;136(6):1227-1235.

22. Rossi GP, Sacchetto A, Chiesura-Corona M, De Toni R, Gallina M, Feltrin GP, Pessina AC. Identification of the etiology of primary aldosteronism with adrenal vein sampling in patients with equivocal computed tomography and magnetic resonance findings: results in 104 consecutive cases. J Clin Endocrinol Metab. 2001;86(3):1083-1090.

23. Carr CE, Cope C, Cohen DL, Fraker DL, Trerotola SO. Comparison of sequential versus simultaneous methods of adrenal venous sampling. J Vasc Interv Radiol. 2004;15(11):1245-1250.

24. Daunt N. Adrenal vein sampling: how to make it quick, easy, and successful. Radiographics. 2005;25(Suppl 1):S143-158.

25. Freel EM, Stanson AW, Thompson GB, Grant CS, Farley DR, Richards ML, Young WF, Jr. Adrenal venous sampling for catecholamines: a normal value study. J Clin Endocrinol Metab. 2010;95(3):1328-1332.

26. Giacchetti G, Ronconi V, Lucarelli G, Boscaro M, Mantero F. Analysis of screening and confirmatory tests in the diagnosis of primary aldosteronism: need for a standardized protocol. J Hypertens. 2006;24(4):737-745.

27. Martins JM, do Vale S, Carrilho B, Saldanha C, Martins e Silva J: Adrenal steroidogenesis in inappropriate high blood pressure [abstract]. J Hypertens 2004, 22(Suppl 2):190.

28. Speiser PW, Azziz R, Baskin LS, Ghizzoni L, Hensle TW, Merke DP, Meyer-Bahlburg HF, et al. Congenital adrenal hyperplasia due to steroid 21-hydroxylase deficiency: an Endocrine Society clinical practice guideline. J Clin Endocrinol Metab. 2010;95(9):4133-4160. 